\title{
Thoracic endometriosis: a case report and review of the literature
}

\author{
Cheng Chen", Kui Zhai", Yang Tang, Wendong Qu, Jiebin Zuo, Xixian Ke, Yongxiang Song \\ Department of Thoracic Surgery, The Affiliated Hospital of Zunyi Medical University, Guizhou, China \\ \#These authors contributed equally to this paper as co-first author. \\ Correspondence to: Yongxiang Song; Xixian Ke, PhD. Department of Thoracic Surgery, The Affiliated Hospital of Zunyi Medical University, 149 \\ Dalian Road, Zunyi, Guizhou 563000, China. Email: songtang2004@163.com; kexixian@zmu.edu.cn.
}

\begin{abstract}
Thoracic endometriosis is characterized by the presence of normal functioning endometrial tissues in normal pleural, diaphragm, or lung parenchyma, and main clinical symptoms include pneumothorax, menstrual hemothorax, menstrual hemoptysis, and pulmonary nodules. Chest X-ray (CXR), computed tomography (CT), magnetic resonance imaging (MRI), bronchoscopy, and surgical biopsy could be applied to the diagnosis of TE. Both drug therapy and surgical treatment were widely used to treat this disease, but no theory was used to guide the choice of treatment options. This paper introduces a case of menstrual hemoptysis due to endometriosis, and the final surgical treatment was chosen. The patient recovered well postoperatively and reported no hemoptysis during 2 months of follow-up. Reexamination of the chest through CT showed no ground-glass lesions or pulmonary exudative lesions. We make the following recommendations for patient selection when considering a surgical approach to the treatment of TE. Patients for whom surgery should be considered are those who (I) do not respond to drug therapy or relapse once drug therapy is withdrawn, (II) cannot tolerate drug therapy or who may wish to get pregnant in the near future (III) have limited lesions which are able to be completely removed during surgery. Patients in whom surgery is not recommended include those who have extensive lesions which cannot be surgically removed, including those with diaphragm or pleural involvement as the diseased tissues must be completely removed to avoid recurrence, and those who are unfit for surgery.
\end{abstract}

Keywords: Thoracic endometriosis (TE); hemoptysis during menstruation; case report

Submitted Jan 08, 2021. Accepted for publication Mar 12, 2021.

doi: $10.21037 /$ apm-21-280

View this article at: http://dx.doi.org/10.21037/apm-21-280

\section{Introduction}

Thoracic endometriosis (TE) manifests as a series of symptoms caused by normal functioning endometrial tissues appearing in normal pleural, diaphragm or lung parenchyma (1). Endometriosis affects $6-10 \%$ of women of childbearing age (2) and thoracic endometriosis is even rarer, no relevant statistics was reported yet. The main clinical symptoms include pneumothorax (73\%), menstrual hemothorax (14\%), menstrual hemoptysis (7\%), and pulmonary nodules (6\%) (3). While the pathogenesis of TE is unclear, currently several hypotheses exist. (I) Coelomic metaplasia theory: pleural epithelial cells from the same source as the endometrium could be transformed into functional endometrial epithelial cells owing to the long- term action of estrogen (3). There have also been reports of male patients with pulmonary endometriosis due to longterm estrogen stimulation (4). (II) Retrograde menstruation theory: when menstruation occurs, the fluid within the endometrium flows back from the fimbria of the fallopian tube and abdominal fluid with endometrial cells attach to the right diaphragm via the sickle ligament, resulting in congenital diaphragmatic defects commonly located on the right side of the chest cavity causing TE mostly on the right side (5). (III) Lymphatic and hematogenous dissemination theory: after uterine cavity surgery, endometrial cells are transferred to the lungs and possibly other locations through the lymphatic vessels (6).

A variety of tests are applied to the diagnosis of TE, including chest X-ray (CXR), computed tomography (CT), 
magnetic resonance imaging (MRI), bronchoscopy, and surgical biopsy, while both medical and surgical approaches are used in treatment. The principle of medical treatment for TE is to inhibit the pituitary-gonad axis£ $\neg$ which can be achieved with oral contraceptives, progesterone agonists, gonadotropin releasing hormone agonists, and danazol. While some authors hold that medications should be initiated within a short period of time from diagnosis (7), unacceptable side effects can occur such as amenorrhea, vaginal dryness, virilization, and lower limb edema, even though these side effects gradually disappear after medication is ceased. The purpose of surgical treatment is to completely remove the lesion (8). This paper reports on a patient who recovered well after surgical treatment.

We present the following case in accordance with the CARE reporting checklist (available at http://dx.doi. org/10.21037/apm-21-280).

\section{Case presentation}

A 19-year-old female-patient attended our hospital in August 2020 stating that she had repeatedly experienced hemoptysis during menstruation for 3 months. The hemoptysis volume was about $15 \mathrm{~mL}$ each time, was red in color, and disappeared after menstruation. She reported three abortion and curettages, the most recent being 1 year ago, and a 2-year history of smoking 10 cigarettes per day. There were no abnormalities in routine blood and blood biochemical examination after admission. In July 2020, the patient had undergone a chest CT examination during menstruation, and this showed exudative changes of the right middle lung (Figure 1A). During this period, the patient had no symptoms of cough or fever. In August 2020, the patient underwent a further chest CT examination outside of her menstrual period, which showed that the large exudative lesions in the right middle lung had been absorbed, and only a small amount of ground glass lesions remained (Figure 1B). Subsequently, the patient was diagnosed with TE, and the right middle lung was completely surgically removed. This disease needed to be differentiated from tuberculosis, lymphangiomyomatosis and lung infection. The patient had no fever or sputum expectoration and no increased neutrophil, so we did not consider she had lung infection. She never had a history of tuberculosis. Her chest CT did not support the diagnosis of lymphangiomyomatosis. Post-surgical pathological results showed the test object was the right middle lung tissue, and large hemorrhage foci and old bleeding could be seen in the alveolar cavity. Scattered glandular epithelial cells were observed in the hemorrhage, and nests of epithelial cells could be seen in the lumen of individual blood vessels, consistent with the diagnosis. Immunohistochemical results showed: 1\#4\#CK (+); ER (-); PR (-) (Figure 1C). The patient recovered well postoperatively and reported no hemoptysis during 2 months of follow-up. Reexamination of the chest through CT showed no ground-glass lesions or pulmonary exudative lesions (Figure 1D).

All procedures performed in studies involving human participants were in accordance with the ethical standards of the institutional and/or national research committee(s) and with the Helsinki Declaration (as revised in 2013). Written informed consent was obtained from the patient.

\section{Discussion}

We chose to remove the patient's right middle lung for the following reasons. Firstly, the patient's lesion was limited to the right middle lung and did not spread to other lung lobes and she had no pleural effusion or pneumothorax strongly suggesting there was no diaphragm or pleural disease (which was confirmed at operation). On this basis it was possible to isolate and remove the diseased segment without impacting on other lung regions. In addition, the patient had a large lesion area which could not be partially resected and we considered it important to completely remove the diseased tissue to avoid the possibility of recurrence, although some authors have reported that local resection of the lesion only improved the symptoms of hemoptysis during the period of the patient's menstruation and did not offer a complete cure $(3,9,10)$. A second reason we opted for surgery in this case was that despite there being reports that long-term drug treatment offered a reasonable alternative for the treatment of TE (11-13), the patient in this case could not tolerate the side effects of drug treatment to the extent that she refused it and requested surgery. Finally, we chose surgery in this case because the patient was young and her lung function and physical condition were appropriate to fully tolerate the operation.

The patient was followed up for 2 months, and hemoptysis did not reappear, indicating that the surgical treatment was effective. In conclusion, we make the following recommendations for patient selection when considering a surgical approach to the treatment of TE. Patients for whom surgery should be considered are those who (I) do not respond to drug therapy or relapse 

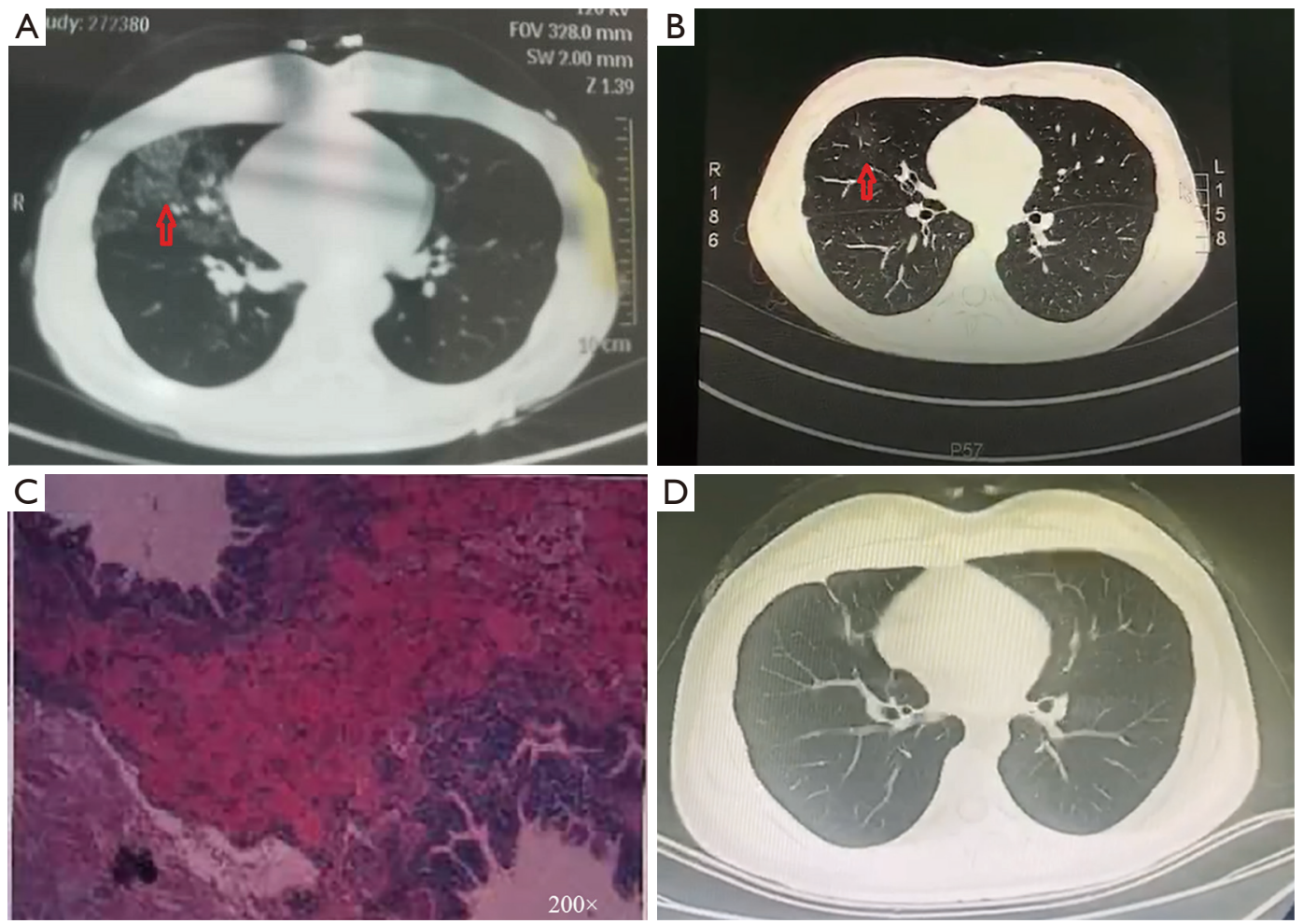

Figure 1 Chest CT (Computed tomography) and postoperative pathological results of the patient. (A) The chest CT examination in the preoperative menstruation period. Large exudative lesions can be observed in the right middle lung (pointed by the arrow in A). (B) Chest CT examination after menstruation shows most of the exudative lesion of the right middle lung has been absorbed, and only a small amount of ground glass lesions remain (pointed by the arrow in B). (C) The pathological results after surgery show the test object was the right middle lung tissue, and large hemorrhage foci and old bleeding can be seen in the alveolar cavity. Scattered glandular epithelial cells are seen in the hemorrhage, and nests of epithelial cells in individual blood vessel lumen, consistent with the endometriosis changes in the right middle lung. The immunohistochemical results showed (TE staining): 1\#4\#CK (Cytokeratin): positive (+); ER (estrogen receptor): negative (-); PR (progesterone receptor): negative (-). (D) Reexamination of the chest CT at 2 months after surgery shows no exudative lesions or ground-glass lesions.

once drug therapy is withdrawn; (II) cannot tolerate drug therapy or who may wish to get pregnant in the near future; (III) have limited lesions which are able to be completely removed during surgery. Patients in whom surgery is not recommended include those who have extensive lesions which cannot be surgically removed, including those with diaphragm or pleural involvement as the diseased tissues must be completely removed to avoid recurrence, and those who are unfit for surgery. To minimize the likelihood of recurrence, patients could be treated with drugs postoperatively.

\section{Acknowledgments}

Funding: This research was supported by the National
Natural Science Foundation of China (grant number 81960532).

\section{Footnote}

Reporting Checklist: The authors have completed the CARE reporting checklist. Available at http://dx.doi.org/10.21037/ apm-21-280

Conflicts of Interest: All authors have completed the ICMJE uniform disclosure form (available at http://dx.doi. org/10.21037/apm-21-280). The authors have no conflicts of interest to declare.

Etbical Statement: The authors are accountable for all 
aspects of the work in ensuring that questions related to the accuracy or integrity of any part of the work are appropriately investigated and resolved. All procedures performed in studies involving human participants were in accordance with the ethical standards of the institutional and/or national research committee(s) and with the Helsinki Declaration (as revised in 2013). Written informed consent was obtained from the patient.

Open Access Statement: This is an Open Access article distributed in accordance with the Creative Commons Attribution-NonCommercial-NoDerivs 4.0 International License (CC BY-NC-ND 4.0), which permits the noncommercial replication and distribution of the article with the strict proviso that no changes or edits are made and the original work is properly cited (including links to both the formal publication through the relevant DOI and the license). See: https://creativecommons.org/licenses/by-nc-nd/4.0/.

\section{References}

1. Adesanya OA, Kolawole OE. Thoracic endometriosis syndrome: Cutting the gordian knot - A case report and review of the literature. Int J Surg Case Rep 2020;66:68-71.

2. McCann MR, Schenk WB, Nassar A, et al. Thoracic endometriosis presenting as a catamenial hemothorax with discordant video-assisted thoracoscopic surgery. Radiol Case Rep 2020;15:1419-22.

3. Maniglio P, Ricciardi E, Meli F, et al. Catamenial pneumothorax caused by thoracic endometriosis. Radiol Case Rep 2017;13:81-5.

Cite this article as: Chen C, Zhai K, Tang $\mathrm{Y}, \mathrm{Qu}$ W, Zuo J, Ke X, Song Y. Thoracic endometriosis: a case report and review of the literature. Ann Palliat Med 2021;10(3):35003503. doi: $10.21037 /$ apm-21-280
4. Kawaguchi Y, Hanaoka J, Ohshio Y, et al. Diagnosis of thoracic endometriosis with immunohistochemistry. J Thorac Dis 2018;10:3468-72.

5. Vercellini $\mathrm{P}$, Abbiati A, Viganò $\mathrm{P}$, et al. Asymmetry in distribution of diaphragmatic endometriotic lesions: evidence in favour of the menstrual reflux theory. Hum Reprod 2007;22:2359-67.

6. Alifano M, Trisolini R, Cancellieri A, et al. Thoracic endometriosis: current knowledge. Ann Thorac Surg 2006;81:761-9.

7. Pankratjevaite L, Samiatina-Morkuniene D. A case report of thoracic endometriosis - A rare cause of haemothorax. Int J Surg Case Rep 2017;33:139-42.

8. Rawala MS, Khaliq MF, Iqbal MA, et al. A Rare Case of Cyclical Hemothorax: Thoracic Endometriosis Syndrome. Case Rep Pulmonol 2018;2018:9830797.

9. Bala A, Salim RA, Deliwala S, et al. Cyclical Hemoptysis and Pelvic Pain in a Young Female: A Sign of Thoracic Endometriosis Syndrome. Cureus 2020;12:e11078.

10. Yukumi S, Suzuki H, Morimoto M, et al. Two young women with left-sided pneumothorax due to thoracic endometriosis. Intern Med 2016;55:3491-3.

11. Alwadhi S, Kohli S, Chaudhary B, et al. Thoracic Endometriosis-A Rare Cause of Haemoptysis. J Clin Diagn Res 2016;10:TD01-TD2.

12. Chatra PS. Thoracic endometriosis: a case report. J Radiol Case Rep 2012;6:25-30.

13. Hwang SM, Lee CW, Lee BS, et al. Clinical features of thoracic endometriosis: A single center analysis. Obstet Gynecol Sci 2015;58:223-31.

(English Language Editor: B. Draper) 